\title{
Rancang Bangun Sistem Maklumat Masjid Berbasis Android Studi Kasus Masjid Jami” "Baitunnur” Desa Kedungrejo Kecamatan Pakis Kabupaten Malang
}

\author{
Mukhammad Erif Fanani ${ }^{1)}$, Yoyok Seby Dwanoko ${ }^{2)}$, Hari Lugis Purwanto ${ }^{3)}$ \\ 1, 2, 3) Program Studi Sistem Informasi, Universitas Kanjuruhan Malang, Indonesia \\ Email Penulis: erifmoker@gmail.com ${ }^{1)}$, yoyokseby@unikama.ac.id ${ }^{2)}, \underline{\text { hari_lugis@unikama.ac.id }}^{3)}$
}

\begin{abstract}
Baitunnur Mosque is one of the mosques that performs many religious activities. With the many activities, the takmir uses 2 digital clock running text to manage activity information. Mosque takmir found it difficult to change information on the digital running text clock and the public had difficulty accessing information. So an information system is designed that can facilitate takmir of the mosque in conveying information and facilitating the community in accessing information. As a result the mosque's takmir can convey information and also the public can easily access information. This system is built using the waterfall method. Based on the results of the UAT test which produced a percentage of $82 \%$, takmir of the mosque and the community supported the existence of this information system.
\end{abstract}

Keywords - Mosque Information System, Waterfall, Android

Abstrak. Masjid Baitunnur adalah salah satu masjid yang melakukan banyak kegiatan keagamaan. Dengan banyaknya kegiatan tersebut, takmir menggunakan 2 jam digital running text untuk mengelola informasi kegiatan. Takmir masjid merasa kesulitan dalam mengubah informasi pada jam digital running text dan masyarakat kesulitan dalam mengakses informasi. Maka dirancanglah sistem informasi yang dapat memudahkan takmir masjid dalam menyampaikan informasi dan memudahkan masayarakat dalam mengakses informasi. Hasilnya takmir masjid dapat menyampaikan informasi dan juga masyarakat dapat mengakses informasi dengan mudah. Sistem ini dibangun dengna menggunakan metode waterfall. Berdasarkan hasil uji UAT yang menghasilkan prosentase $82 \%$, takmir masjid dan masyarakat mendukung adanya sistem informasi ini.

Kata Kunci - Sistem Maklumat Masjid, Waterfall, Android

\section{A. Latar Belakang}

\section{Pendahuluan}

Sholat merupakan ibadah wajib bagi umat Islam di seluruh dunia. Keutama'an sholat adalah dikerjakan berjama'ah dan tepat waktu. Keutama'an lain yaitu dikerjakan di masjid. Masjid adalah tempat ibadah umat Islam yang artinya tempat sujud. Fungsi Masjid tidak hanya untuk mengerjakan sholat saja, tapi juga bisa digunakan untuk melakukan kegiatan keagamaan lainnya contoh, perayaan hari besar Islam, ceramah, kajian agama, tadarus Al-Qur'an, dan belajar Al-Qur'an. Untuk melaksanakan kegiatan - kegiatan tersebut, perlu adanya informasi dan jadwal agar kegiatan dapat berjalan dengan lancar. Dalam penyampaian informasi atau jadwal kegiatan saat ini sudah banyak masjid yang menggunakan jam digital masjid yang dikelola oleh takmir masjid.

Masjid Baitunnur adalah salah satu masjid yang melakukan banyak kegiatan keagamaan. Dengan banyaknya kegiatan keagamaan di Masjid Batunnur, takmir menggunakan 2 jam digital running text dan 1 TV LCD untuk mengelola kegiatan yang ada di masjid. Jam digital running text digunakan untuk menunjukkan waktu sholat dan TV LCD yang sudah terhubung dengan VCD digunanakan untuk memutar video, gambar dan menyampaikan informasi. Takmir merasa kesulitan karena untuk melakukan pengaturan ulang pada jam digital running text harus dilakukan oleh pembuat itu sendiri. Takmir juga merasa kesulitan dalam menyampaikan informasi dikarenakan dalam penggunaan TV LCD takmir harus menyimpan data ke dalam $C D$ yang dapat diputar pada $V C D$ sehingga membutuhkan waktu banyak bagi takmir dalam menyampaikan informasi. Disamping itu, dengan adanya permasalahan tersebut menyebabkan masyarakat kesulitan dalam mengakses informasi yang ada pada masjid.

Dari permasalahan diatas, dirancanglah sebuah sistem informasi yang dapat memudahkan takmir masjid dalam menyampaikan informasi, mengganti atau mengubah pengaturan dengan cepat, efisien, dan juga memudahkan masyarakat dalam mengakses atau menerima informasi pada masjid Baitunnur.

\section{B. Batasan Masalah}

Keterbatasan pada penelitian ini adalah Ketersediaan media seperti TV LED dan TV Box berbasis android yang mendukung pemanfaatan sistem.

\section{Tujuan Penelitian}

Berdasarkan uraian diatas maka tujuan dari penelitian ini adalah mempermudah takmir masjid dalam menyampaikan informasi, memudahkan masyarakat dalam mengakses informasi dan takmir masjid dapat melakukan pengaturan pada aplikasi sesuai kebutuhan. 


\section{Referensi Penelitian}

Adapun jurnal penelitian sebagai rujukan yang telah berhasil "Alat Pengingat Waktu Sholat Di Masjid BerbasisRaspberry Pi" alat yang dibuat dilengkapi dengan pemberitahuan jika sudah masuk waktu sholat dengan alarm yang dapat diubah-ubah sesuai keinginan. Alat ini juga dilengkapi dengan slide show berupa gambargambar ataupun video-video yang telah disimpan di perangkat dan dapat menampung dengan jumlah yang cukup banyak. [3]

Jurnal rujukan "Rancang Bangun Sistem Informasi Jadwal Sholat Berbasis Tv Android" Sistem yang telah dirancang dapat berjalan dengan baik. Dapat menampil kan jadwal sholat yaitu lima waktu sholat wajib, menghitung jeda waktu sholat menuju waktu sholat selanjutnya, menampilkan waktu untuk menghitung mundur ke iqomah, menampilkan video dan jadwal kajian. [2]

Jurnal rujukan "Perancangan Sistem Informasi Manajemen Masjid Baiturrahim Berbasis Web “ ini telah sesuai rencana dan tujuan awal. Sistem informasi manajemen Masjid Baiturrahim berbasis web ini memudahkan takmir masjid dalam memanajemen kegiatan masjid serta membantu masyarakat dalam mencari informasi tentang Masjid Baiturrahim dengan efektif dan efisien. [6]

\section{METODE}

\section{A. Waterfall}

Waterfall yaitu model air terjun kadang dinamakan siklus hidup klasik (classic life cyle), dimana pada hal ini dilakukan pendekatan yang berurutan (sekuensial) pada pengembangan perangkat lunak. Pengembangannya dimulai dari spesifikasi kebutuhan oleh pengguna dan dilanjutkan dengan tahapan analisis kebutuhan, desain produk, pemrograman, pengujian dan implementasi. yang diakhiri dengan menghasilkan dukungan berkelanjutan pada peranggkat lunak.[5]

Model waterfall ini dipilih karena menggunakan pendekatan yang sistematis atau bertahap dalam pengembanganya. Komponen - komponen dari model waterfall dijelaskan pada gambar 1.

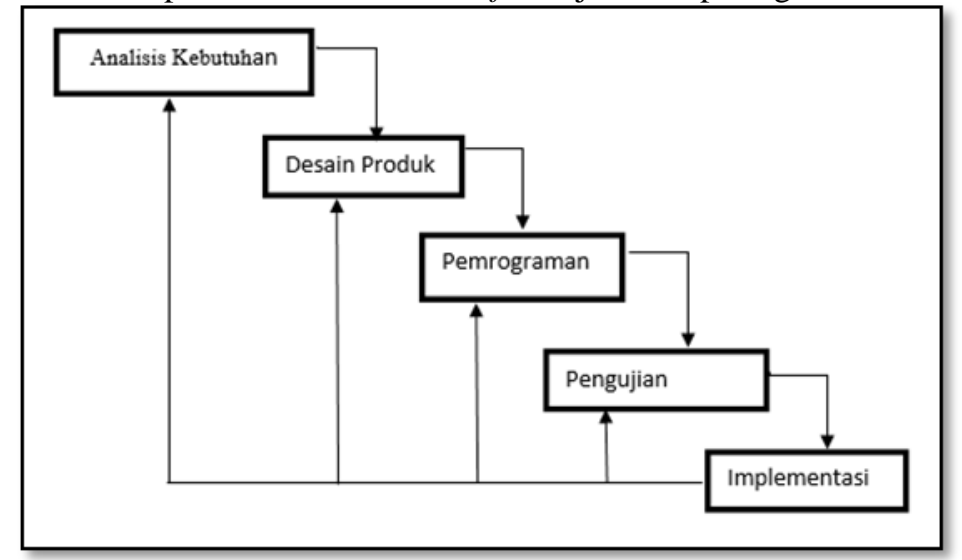

Gambar 1. Model Waterfall

Berikut adalah tahapan yang perlu dilakukan dalam membangun sistem menggunakan metode waterfall yaitu:

1. Analisis kebutuhan, yaitu proses pengumpulan data untuk menentukan seperti apa sistem yang dibutuhkan oleh user.

2. Desain produk, yaitu proses desain pembuatan program perangkat lunak dan representasi antar muka. Tahap ini mentranslasi kebutuhan perangkat lunak dari tahap analisis kebutuhan ke representasi desain agar dapat diimplementasikan menjadi sistem.

3. Pemrograman, yaitu untuk mentranslasikan hasil tahap desain produk ke dalam program perangkat lunak.

4. Pengujian, yaitu memastikan bahwa semua fungsi dapat berjalan dengan baik. Hal ini dilakukan untuk mengurangi kesalahan dan memastikan keluaran yang dihasilkan telah sesuai dengan hasil analisis dan desain.

5. Implementasi, yaitu hasil dari pengujian yang diterapkan langsung pada tempat dimana sistem ini digunakan.

\section{B. Unified Modelling Language (UML)}

Unified Modeling Language adalah sebuah bahasa yang menjadi standar dalam industri untuk dapat merancang dan mendokumentasikan sistem. Dengan menggunakan $U M L$ kita dapat membuat berbagai model untuk semua jenis piranti lunak dimana aplikasi juga dapat berjalan dalam piranti keras sistem operasi, pada jaringan apapun dan dapat ditulis dalam bahasa pemrograman apapun.

\section{Use Case Diagram}


Pada Use case diagram ini merupakan tahapan pemodelan untuk melakukan sistem informasi yang akan dibuat. Use case digunakan untuk mengetahui fungsi apa saja yang ada di dalam sistem informasi dan actor yang berhak menggunakan fungsi-fungsi tersebut. [1]

\section{Black Box Testing}

Pada black box testing ini digunakan untuk menguji fungsi-fungsi khusus dari system yang telah selesai dirancang. dilakukan pengecekan sistem untuk dapat mengetahui kebenaran pengujian dilihat pada keluaran yang dihasilkan dari data atau kondisi masukan. Dari keluaran yang dapat dihasilkan, kemampuan program telah memenuhi kebutuhan pengguna dan dapat diukur sekaligus dapat diketahui kesalahannya. [7]

\section{Hasil dan Pembahasan}

\section{A. Analisis Kebutuhan}

Dalam tahap ini dilakukan observasi dan wawancara dengan mengajukan beberapa pertanyaan kepada takmir masjid dan masyarakat. Setelah dilakukan observasi dan wawancara, menghasilkan tabel kebutuhan fungsional dan non fungsional dengan menyesuaikan kebutuhan takmir dan masyarakat.

Kebutuhan fungsional adalah kebutuhan yang berisi proses pada sistem. Sedangkan kebutuhan non fungsional adalah kebutuhan yang menitik beratkan pada prilaku yang dimiliki sistem. Kebutuhan fungsioanl dapat dilihat pada tabel 1 .

Tabel 1. Kebutuhan Fungsional

\begin{tabular}{|c|c|c|}
\hline No & Fungsi & Keterangan \\
\hline 1 & Login & $\begin{array}{l}\text { - Pengguna memasukan username dan password untuk } \\
\text { dapat masuk ke sistem }\end{array}$ \\
\hline 2 & Daftar & $\begin{array}{l}\text { - Pengguna melakukan pendaftaran untuk dapat } \\
\text { melakukan login }\end{array}$ \\
\hline 3 & Manajemen pengaturan & $\begin{array}{ll}\text { - } & \text { Pengguna dapat mengatur nama masjid } \\
\text { - } & \text { Pengguna dapat mengubah data waktu sholat } \\
\text { - } & \text { Pengguna dapat mengatur audio } \\
\text { - } & \text { Pengguna dapat mengatur waktu mundur } \\
\text { - } & \text { Pengguna dapat menambah jadwal ceramah } \\
\text { - } & \text { Pengguna dapat mengganti gambar slide } \\
\text { - } & \text { Pengguna menambah video } \\
\text { - } & \text { Pengguna dapat mengubah waktu dunia } \\
\text { - } & \text { Pengguna dapat mengirim pengumuman }\end{array}$ \\
\hline 4 & $\begin{array}{l}\text { Mastering data waktu } \\
\text { sholat }\end{array}$ & $\begin{array}{l}\text { - Pengguna dapat menambah, mengubah dan } \\
\text { menghapus waktu sholat }\end{array}$ \\
\hline 5 & Mastering hari besar & $\begin{array}{l}\text { - Pengguna dapat menambah, mengubah dan } \\
\text { menghapus hari besar islam }\end{array}$ \\
\hline 6 & Mastering tanggal hijriyah & $\begin{array}{l}\text { - Pengguna dapat menambah, mengubah dan } \\
\text { menghapus tanggal hijriyah }\end{array}$ \\
\hline 7 & Akses Informasi & - $\quad$ Pengguna dapat mengakses informasi \\
\hline
\end{tabular}

Berikut adalah tabel kebutuhan non fungsional dapat dilhat pada tabel 2

Tabel 2. Kebutuhan Non Fungsional

\begin{tabular}{llc}
\hline No & \multicolumn{1}{c}{ Kebutuhan } & Keterangan \\
\hline 1 & User Friendly & Usability \\
\hline 2 & Menggunakan TV Box berbasis android & Portability \\
\hline 3 & Menggunakan TV LCD & Portability \\
\hline
\end{tabular}




\section{B. Desain Produk}

Desain produk yaitu untuk melakukan tahapan pembuatan desain program perangkat lunak, pemodelan dan desain tampilan untuk sistem maklumat masjid berbasis android.

1. Desain tampilan ini adalah peneliti akan melakukan desain untuk tampilan aplikasi atau user interface design.

2. Pemodelan yang dimaksud ini adalah pembuatan $U M L$ yang bertujuan untuk memperjelas dan mempermudah proses dan alur pengembangan sistem maklumat masjid.

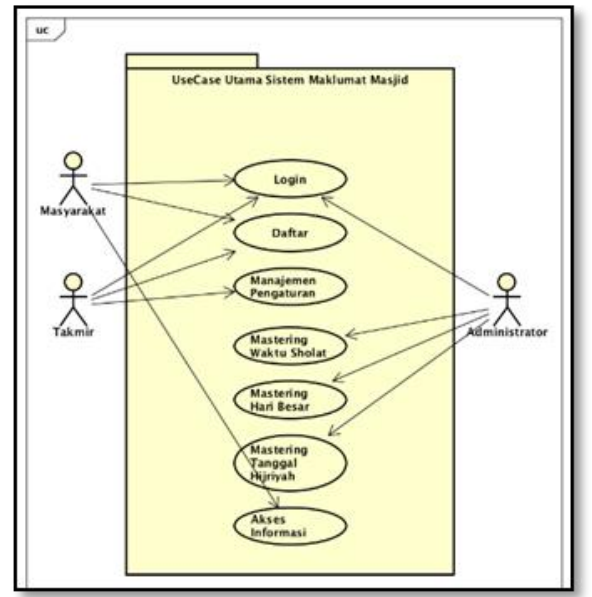

Gambar 2 Use Case Diagram Utama

1. Login digunakan untuk melakukan validasi username dan password.

2. Daftar digunakan untuk mendaftarkan biodata agar dapat melakukan login.

3. Mastering waktu sholat digunakan oleh administrator untuk mengolah waktu sholat.

4. Mastering hari besar digunakan oleh administrator untuk mengolah data hari besar.

5. Mastering tanggal hijriyah digunakan oleh administrator untuk mengelola data tanggal hijriyah.

6. Manajemen pengaturan digunakan oleh takmir untuk melakukan pengaturan pada SIMAS dengan langsung mapupun jarak jauh.

7. Akses Informasi oleh masyarakat untuk mendapatkan informasi pada SIMAS.

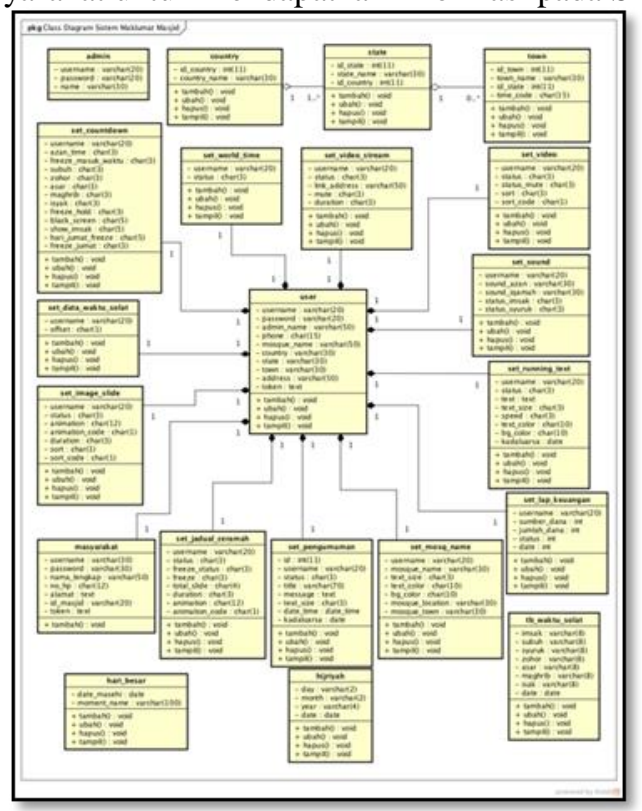

Gambar 3 Class Diagram

Dalam Class Diagram ini terdapat 21 class yang mempresentasikan tabel yang akan digunakan didalam sistem antara lain: (1) admin (2) User (3) Country (4) State (5) Twon (6) Hari Besar (7) Hijriyah (8) Waktu Sholat (9) Set Countdown (10) Set World Time (11) Set Vidio Strem (12) Set Vidio (13) Set Running Text (14) Set Sound (15) Set Data Waktu Sholat (16) Set Image Slide (17) Set Mosque Name (18) Set Jadual Kuliah (19) Masyarakat (20) Set Pengumuman (21) Set Lap Keuangan.

Pembuatan desain GUI pada setiap halaman sistem. Yang digunakan untuk membuat desain GUI yaitu 
menggunakan aplikasi balsamiq mockup. Dapat dilihat pada gambar 4.

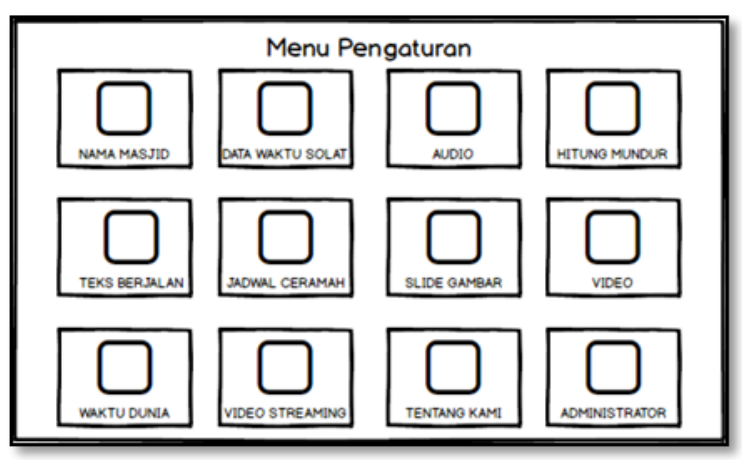

Gambar 4 Desain GUI

\section{Pemrograman}

Pada pembuatan program sistem maklumat masjid disesuaikan dengan desain produk yang sudah direncanakan, setelah itu dilakukan pemrograman.

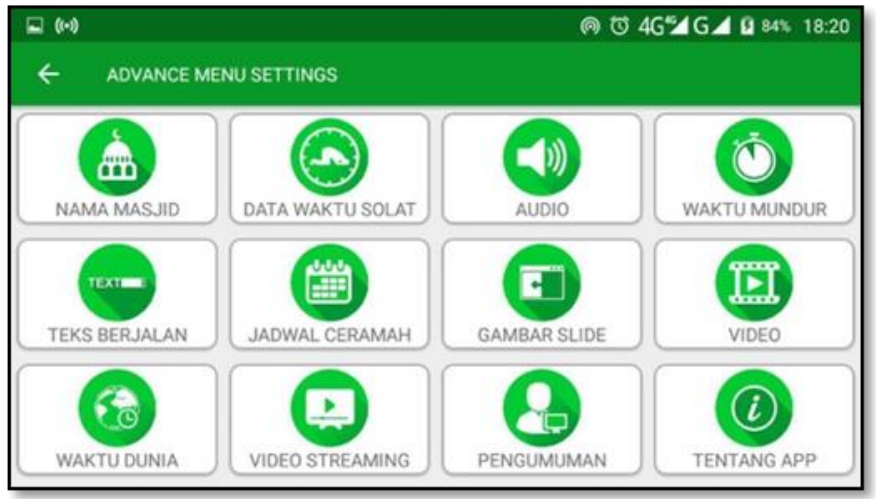

\section{Pengujian}

Gambar 5. User Interface Sistem Maklumat Masjid

Setelah pemrograman selesai kemudian dilakukan pengujian sistem dengan blackbox testing. Pengujian dilakukan dengan membuktikan bahwa semua objek dalam sistem dapat berjalan sesuai fungsi yang ditentukan. Pengujian ini dilakukan dengan menguji semua fungsi. Hasil dari pengujian sistem blackbox testing dapat dilihat pada tabel 3 .

Tabel 3. Uji Black Box

\begin{tabular}{|c|c|c|c|c|c|}
\hline No & Data Uji & Input & Diharapkan & Output & Kesimpulan \\
\hline UCBL & Login & $\begin{array}{l}\text { Username dan } \\
\text { password }\end{array}$ & $\begin{array}{l}\text { Masuk ke menu } \\
\text { utama }\end{array}$ & Menu utama & Berhasil \\
\hline UCBD & Daftar & biodata & Daftar berhasil & Daftar berhasil & Berhasil \\
\hline UCBMP & $\begin{array}{l}\text { Manajemen } \\
\text { Pengaturan }\end{array}$ & atribut pengaturan & $\begin{array}{l}\text { Menyimpan informasi } \\
\text { sesuai kofigurasi. }\end{array}$ & $\begin{array}{l}\text { Data tersimpan } \\
\text { sesuai } \\
\text { konfigurasi }\end{array}$ & Berhasil \\
\hline UCBMW & $\begin{array}{l}\text { Mastering Waktu } \\
\text { Sholat }\end{array}$ & $\begin{array}{l}\text { Tanggal, imsak } \\
\text { duha, dzuhur } \\
\text { ashar, maghrib, } \\
\text { isyak }\end{array}$ & $\begin{array}{l}\text { Data waktu sholat } \\
\text { dapat tersimpan }\end{array}$ & $\begin{array}{l}\text { Data waktu } \\
\text { sholat tersimpan }\end{array}$ & Berhasil \\
\hline UCBMH & $\begin{array}{l}\text { Mastering Hari } \\
\text { Besar }\end{array}$ & Tanggal, moment. & $\begin{array}{l}\text { Data haribesar dapat } \\
\text { tersimpan. }\end{array}$ & $\begin{array}{l}\text { Data hari besar } \\
\text { tersimpan }\end{array}$ & Berhasil \\
\hline UCBT & $\begin{array}{l}\text { Mastering } \\
\text { Tanggal Hijriyah }\end{array}$ & $\begin{array}{l}\text { Tanggal, } \\
\text { hari hijriyah, } \\
\text { bulan hijriyah, } \\
\text { tahun hijriyah }\end{array}$ & $\begin{array}{l}\text { Data tanggal hijriyah } \\
\text { dapat tersimpan }\end{array}$ & $\begin{array}{l}\text { Data tanggal } \\
\text { hijriyah } \\
\text { tersimpan }\end{array}$ & Berhasil \\
\hline
\end{tabular}




\section{E. Implementasi}

\section{A. Mastering Data Waktu Sholat}

Mastering data waktu sholat digunakan oleh administrator untuk menambah, mengubah, dan menghapus waktu sholat sesuai lokasi yang nantinya akan digunakan oleh takmir masjid dan masyarakat. Form mastering data waktu sholat dapat dilihat pada gambar 6.

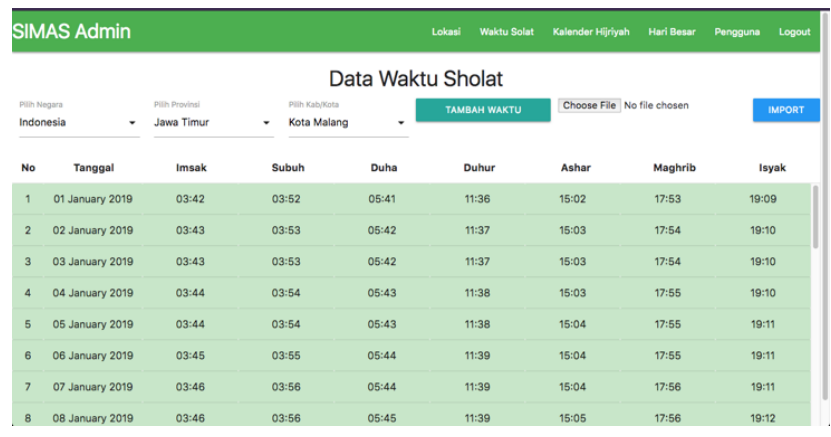

Gambar 6. Mastering Data Waktu Sholat

\section{B. Mastering Tanggal Hijriyah}

Mastering tanggal hijriyah digunakan oleh administrator untuk menambah, mengubah, dan menghapus tanggal hijriyah yang nantinya akan digunakan oleh takmir masjid dan masyarakat. Form mastering tanggal hijriyah dapat dilihat pada gambar 7.

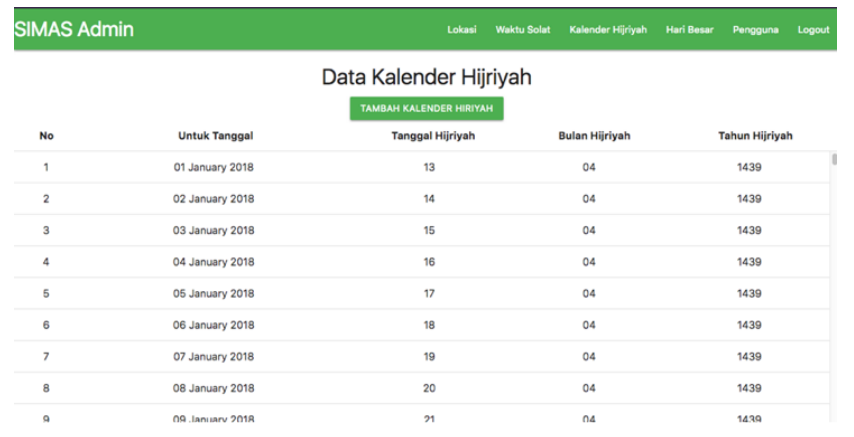

Gambar 7. Mastering Tanggal Hijriyah

\section{Mastering Hari Besar Islam}

Mastering hari besar islam digunakan oleh administrator untuk menambah, mengubah, dan menghapus informasi hari besar islam yang nantinya akan digunakan oleh takmir masjid dan masyarakat. Form mastering data waktu sholat dapat dilihat pada gambar 8 .

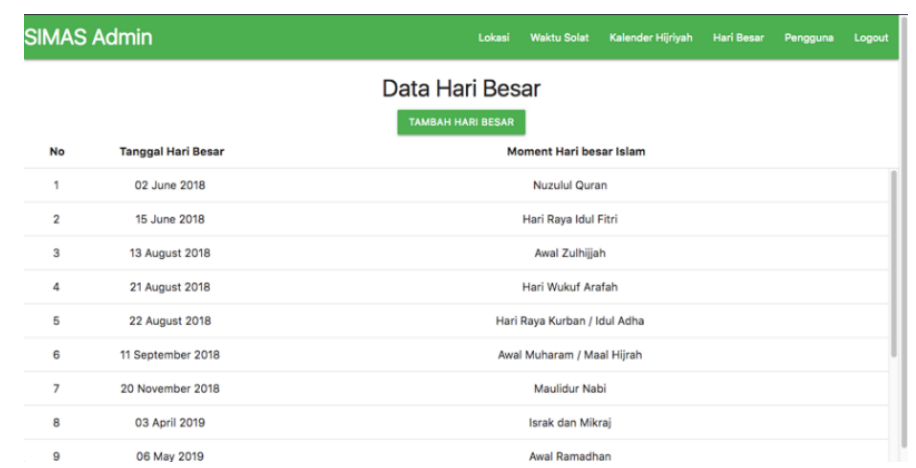

Gambar 8. Mastering Hari Besar 


\section{KESIMPULAN}

Setelah melakukan penelitian ini, maka dapat diambil kesimpulan sebagai berikut:

1. SIMAS dapat dibangun dengan menggunakan metode waterfall yang menghasilkan login, daftar, mastering waktu sholat, mastering hari besar, mastering tanggal hijriyah, manajemen pengaturan dan aplikasi simas untuk masyarakat.

2. Berdasarkan hasil uji user acceptance test yang dilakukan kepada takmir masjid dan masyarakat, hasil yang didapat mencapai $82 \%$. Sehingga dapat dinyatakan dengan adanya SIMAS mempermudah takmir dalam menyampaikan informasi dan juga memudahkan masyarakat dalam mengakses informasi.

\section{UCAPAN TERIMA KASIH}

Segala puji bagi Allah SWT yang telah memberikan rahmatnya sehingga penulis dapat menyelesaikan jurnal "Rancang Bangun Sistem Maklumat Masjid Berbasis Android". Dengan segala kerendahan hati penulis mengucapkan banyak terimakasih karena dalam penyusunan jurnal ini penulis mendapatkan banyak bantuan, masukan, bimbingan dari berbagai pihak, sehinngga dapat menyelesaikan penyusunan jurnal ini dengan baik. Maka pada kesempatan ini penulis ingin menyampaikan yang sebesar-besarnya penulis sampaikan kepada:

1. Bapak Djaelani selaku takmir masjid "Baitunnur" yang telah membantu dengan memberikan informasi terkait penelitian yang dilakukan.

2. Terimakasih untuk orang yang terkasih, terimaksih sudah membantu dan membimbing serta memberi saran dalam menyelesaikan tugas akhir ini, semoga allah membalas semua keiklhasanmu.

3. Teman-teman Sistem Informasi Angkatan 2014 (Coding Bahagia) yang sudah memberikan dukungan dan bantuan dalam menyelesaikan jurnal ini. Semua pihak yang tidak dapat disebutkan satu persatu yang telah membantu memberikan dukungan. Akhirnya, semoga segala bantuan yang telah diberikan semua pihak diatas menjadi amalan yang bermanfaat dan mendapatkan balasan dari Allah SWT dan jurnal ini menjadi informasi yang bermanfaat bagi pembaca atau pihak lain yang membutuhkan nya.

\section{REFERENSI}

[1] Hendini Ade. "Pemodelan UML Sistem Informasi Monitoring Penjualan Dan Stok Barang", Jurnal Khatulistiwa Informatika, Vol. IV, No. 2, 108-111, 2016.

[2] Mulyana, dkk. "Rancang Bangun Sistem Informasi Jadwal Sholat Berbasis Tv Android". Jurnal Teknik Komputer Unikom-Komputika Volume 6, No.1, 2017.

[3] Nurwicaksana, dkk. "Alat Pengingat Waktu Sholat Di Masjid BerbasisRaspberry Pi”, Isbn: 978-602-1180-50-1, 2017.

[4] Permana Rio Agus. "UML (UNIFIED MODELLING LANGUAGE)", 50, Di akses dari http://www.academia.edu/16398926/UML_Unified_Modeling_Language, 2015.

[5] Pressman, R. "Rekayasa Perangkat Lunak Pendekatan Praktisi Buku 1”, Yogyakarta: ANDI, 2015.

[6] Reyanda Dwi yatna Putra. "Perancangan Sistem Informasi Manajemen Masjid Baiturrahim Berbasis Web", 14, 2017.

[7] Zulkarnaen. "Metode Pengujian Perangkat Lunak", STMIK Bandung-Bali-SI, 2-3, 2015. 